\title{
On Power, Conventions, and the Varieties of Normativity
}

\author{
LEO ZAIBERT, WISCONSIN ${ }^{*}$
}

In the last few years, philosophers have paid much needed attention to social ontology (Gilbert 1989; Tuomela 1995, 2002). Broadly constructed, social ontology is an attempt to apply the traditional, rigorous methods familiar to metaphysicians to the analysis of entities not traditionally approached metaphysically: the State, its authority, and a host of other social institutions and phenomena, from contracts to credit cards. Of course, these sorts of themes are abundantly discussed by political philosophers (and by historians, sociologists, etc.), but not in the ways that contemporary social ontologists do this. Paraphrasing John R. Searle, part of the impetus behind social ontology is an attempt to see social philosophy as something other than a wholly owned subsidiary of political philosophy. As it turns out, one of the most influential theories about the ontological structure of social reality is Searle's own, as he develops it in his The Construction of Social Reality (Searle 1995). I will here raise one criticism to Searle's social ontology, but some of what I have to say applies to other approaches to social ontology as well.

A brief summary of the problem I shall discuss is the following: (Searle's) social ontology does not take normativity seriously; important types of normative phenomena have no place within (his) social ontology. I am opposing the normative to the descriptive: to say that your shirt is blue is to offer a descriptive claim, to say that your shirt ought to be blue is to present a normative claim. Searle's disregard for normativity in his social ontology is particularly noteworthy in light of the fact that it is precisely in the social world where most normative phenomena arise. Notice, however, that I am not challenging the impetus which seeks to separate social philosophy from political philosophy: it is in fact salutary to attempt to analyze, say, the institution of marriage, independently of the normative position one takes regarding marriage (i.e., whether one thinks it is morally defensible, and so on). But, some social phenomena, as a sheer analytical

\footnotetext{
*With thanks to Alexander von Humboldt Foundation, and to Maurizio Ferraris, Ingvar Johansson, Anna Schur, and Barry Smith.
} 
point, are drenched in normativity in ways which (Searle's) social ontology neglects.

\section{Institutional Logic}

A good way of introducing Searle's social ontology is by taking a look at what he calls "institutional logic" (which is a modified version of deontic logic). There is exactly one primitive logical operation by which institutional reality is created and constituted. It has the form:

We collectively accept, acknowledge, recognize, go along with, etc., that ( $\mathrm{S}$ has the power (S does $\mathrm{A})$ ).

We can abbreviate this formula as:

We accept (S has power (S does A)) (Searle 1995, 111).

This last sentence expresses what Searle calls "the basic structure" of institutional reality; the rest of institutional reality being merely a matter of "Boolean operations" on this basic structure. There is one crucial concept underlying institutional logic, and thereby the whole of Searle's social ontology is "exactly" one. By Searle's own admission, all institutional reality revolves around it. And yet, in spite of the colossal importance this concept has for Searle's social ontology, Searle has very little to say about it.

This is the concept of power, and what follows from Searle's scant remarks is that he uses the expression in a narrow way. By 'power' Searle means 'conventional power'. By 'conventional power', we are to understand a power that a group or an individual contingently grants to other groups or individuals. These powers are modeled after (legal) rights; they flow from what Searle calls constitutive rules (rules which bear resemblance to Rawls' practice rules and to Hart's secondary rules) (Zaibert and Smith 2007). Constitutive rules, usually opposed to regulative rules, create the very possibility of a certain practice, whereas regulative rules merely indicate how independently existing activities are more graciously carried out. For example, in football (soccer), that a player should kick the ball out when a player in the other team is injured is a regulative rule; but that a player (other than the goalie) should not touch the ball with his hands is a constitutive rule. If a player violated a regulative rule of football, he would 
still be playing football, if he 'violated' a constitutive rule, then he would simply not be playing football.

It is not coincidental that I have used a game in order to illustrate constitutive rules, since Searle's social ontology is modeled after games. (I shall return to this point.) Now, within the context of social reality, a driver's license is an instrument through which a government authorizes a person to drive a vehicle, a credit card is an instrument through which a bank authorizes someone to buy things using the bank as creditor, etc., in accordance with the formula presented above, and in accordance with various, overlapping sets of constitutive rules.

Independently of the merits of this "basic structure" of institutional reality vis-à-vis the explanation of some social phenomena, it surely fails to account for important aspects of social reality. And this failure is in part the result of the two interconnected theses presupposed by Searle's narrow account of power already sketched: first, that normativity is wholly a matter of constitutive rules; and second, that these rules are always a matter of conventional agreements.

Searle's "basic structure" of institutional reality can be traced back to his earlier work. (Searle distinguishes institutional from social phenomena. The latter is a subset of the former, and it is characterized by the fact that powers are much more clearly visible in these sorts of phenomena. Searle admits, however, that the difference is a matter of degrees (Searle 1995, 88 ff.).) It was precisely in virtue of the appeal to constitutive rules that Searle, famously, allegedly derived an 'ought' from an 'is'. His social ontology inherits both the felicities and the infelicities of a contribution which appeared first in a very early article entitled "How to Derive 'Ought' from 'Is" Searle 1964). By appealing to the institution of promising (and its constitutive rules), Searle derived an ought from an is - thus casting doubt over whether what most philosophers had for centuries taken to be a very difficult problem was a problem at all.

A simplification of Searle's famous argument runs as follows: from the purely descriptive statement that "A promises to give B five dollars", a normative statement can be derived: "A ought to give B five dollars". (I omit here the intervening steps.) The constitutive rules of promising entail that, if one promises, then one ought to do what one promised to do. And this is to say that someone has the power to demand that we do what we promised to do, etc. This 'ought', that is, this normative statement which Searle allegedly derived from a purely descriptive statement, follows solely from the meaning of promising. 
Searle admitted, however, that whatever relevance this derivation of an 'ought' from an 'is' might have regarding specifically moral normativity, it would be a mere side-effect of his concern with a logical problem about the illocutionary force of certain utterances. According to Searle: we must avoid "lapsing into talk about ethics or morals. We are concerned with 'ought', not with 'morally ought'" (Searle 1969, 176). Yet Searle also, and inconsistently, suggested that this derivation of an 'ought' from an 'is' "solved" the naturalistic fallacy (which he dubbed the naturalistic fallacy fallacy) - a central problem for ethics or morals. This and other suggestions of a similar tenor may have led scores of commentators into erroneously believing that Searle had accomplished something of great relevance for ethics or morals.

The relevance of Searle's early derivation of 'ought' from 'is' for my current purposes is that this gambit, i.e., the appeal to constitutive rules in order to "solve" age-old problems having to do with normativity, remains the central maneuver in Searle's social ontology. To a great extent, Searle's social ontology is just an extension of his seminal views on the nature of promising. Promises, Searle tells us, are present in "all" or "virtually all" speech acts, and these, in turn, are the building blocks of social reality, as they are the conduits through which power is conveyed, created, extinguished, etc. But then, the 'oughts' of Searle's social ontology are as humble as the 'ought' of his early derivation of 'ought' from 'is'. They are all the result of the constitutive rules of phenomena which we ourselves create in this or that way, but that we could have chosen to create differently. A batter who swings at a third strike ought to leave the field all right, insofar as those are the constitutive rules of baseball, but we could change the constitutive rules of baseball (as baseball officials indeed more or less regularly do). There are, then, no robust, 'moral oughts' in Searle's social ontology.

This explains, then, the close connection between Searle's social ontology and games: since he is in fact interested only in non-moral normativity, the normativity of social institutions is just the same normativity of games. The only normativity which is of concern to Searle when he discusses social institutions is on a par with the normativity of games: someone summoned to appear in court, ought to appear in court in quite the same sense that, in chess, bishops ought to move diagonally, or that a footballer must leave the field after being shown a red card, etc. 


\section{Honor}

Surely, however, there is more to social reality than this rather jejune sense of 'ought'. And Searle himself comes close to tackling at least one complication regarding the different types of normativity that are relevant for social ontology which, I believe, find no room within his social ontology. Searle admits that there exists an "interesting exception" to his overarching "only power matters" view of social ontology. The "interesting exception" is what Searle calls "purely honorific" institutional facts. These are institutional facts which do not involve the transmission, creation, cessation, etc. of any power. These are Searle's examples: "receiving a medal, receiving an honorary degree, being voted the most popular person in your class, being elected Miss Alameda County" (Searle 1995, 96). There are also, for Searle, phenomena which are a matter of pure "negative honors" and as such, they are somehow opposed to the sorts of cases just mentioned (though they still are purely honorific); his examples: "being censured for your bad behavior, being reprimanded by your superiors, voted the least popular in your class" (Searle 1995, 97).

These phenomena (both positive and negative honors) do indeed constitute an exception to the central thesis of Searle's social ontology, for they do not conform to the formula containing the "basic structure" of institutional reality. Rather than addressing this exception, however, Searle merely notes it just to summarily dismiss it, suggesting that the exception is in fact merely apparent. For Searle also refers to these purely honorific phenomena as: "limiting cases of the deontic" (Searle 1995, 109), and as "degenerate cases of the deontic" (Searle 1995, 110). By 'deontic', in this context, Searle simply means the paradigmatically institutional, i.e., cases in which powers are transmitted, created, destroyed, etc. Recall that the power we are talking about here is narrow (modeled after legal powers) in the sense explained above. The 'power' to brag about your Miss Alameda County status, for example, is not a power in Searle's social ontology. Moreover, the 'power' that you may have to censure me after I break my promise is not a power either. It is of course not clear at all whether being a "limiting case" is the same as being a "degenerate case", nor whether either (or both) of these two characterizations of the purely honorific are consistent with the claim that they are an exception the basic structure of institutional reality. In any case, these labels are a way of evading the problem that purely honorific (social) phenomena do pose to Searle's social ontology, and thus they render Searle's treatment of purely honorific phenom- 
ena both superficial and obscure. But the problem upon which I wish to focus goes beyond this peculiar amalgam of superficiality and obscurity, since it concerns issues about which Searle is straightforward.

What Searle has in mind, in any case, is the following: the purely honorific cases were in his opinion, at some point, "normal" deontic cases, but with the passing of time, the powers initially associated with them dwindled down, in such a way that now all that remains is the honor, with no attached power. Receiving a medal, for example, at some point involved the transmission (creation, cessation, etc.) of powers ('powers' in the narrow sense explained already), just as becoming Miss Alameda County did, or as being censured did, etc.; now the same phenomenon just has ceased to involve power. While surely this sort of dwindling down may be true in some cases, it is problematic to assert the thesis - à la Searle - as if it held generally for all honorific phenomena. Sometimes censuring someone does involve the transmission (etc.) of some power (even in Searle's narrow sense); so Searle should at the very least tell us why some instances of censuring degenerate into purely honorific institutional facts and others do not. But the crucial objection upon which I wish to focus, again, is that to universalize this explanation seems to entail (or suggest) a denial the existence of the notion of intrinsic value. And, I wish to argue, that any social ontology which ignores intrinsic value (as Searle's does) is deficient.

\section{The Campus War and The Construction of Social Reality}

Very early in his career, Searle wrote a book, The Campus War, in which he discussed the student revolts of the 1960s in the United States (Searle 1971). While in a sense the book is the least philosophical of Searle's major works, the paucity of discussions connecting this book with the main tenets of Searle's social ontology is still surprising. For after all, The Campus War is a far-reaching analysis of concrete social and institutional phenomena, of the sorts which, one would have imagined, would be supported by Searle's more theoretical writings. And yet, some of the central theses and insights which Searle espoused as he discussed the student revolts of the 1960s are not easily discernible in the later The Construction of Social Reality.

I would like to begin this section by commenting on a common theme found in the two books: Searle's gloss over La Rochefoucauld's dictum whereby "falling in love" would not be possible without pre-existing literary treatments of "falling in love". I do not now wish to discuss whether La 
Rochefoucauld is right about this. Searle seems to believe that La Rochefoucauld is right, and right in virtue of a concept which plays a much more prominent role in The Campus War than in The Construction of Social Reality: dramatic categories. These categories which make falling in love possible have been afforded to us by literature; without Shakespeare's work, for example, your falling in love would either not be possible, or, at least, it would be different from what it is. In his eloquent explanation of student revolts in the United States in the sixties, Searle makes abundant use of these categories. And yet, they are almost totally absent in his recent technical work on social ontology.

In Searle's view, that someone was a "pig" (i.e., a police officer), was by itself a reason to hate him, and, in some cases this fact alone mobilized students to action. Similarly, opposing the "whites' oppression of blacks" was another popular dramatic category, just as being a "radical", or a "revolutionary" were dramatic categories, and, again, these categories were perfectly capable, by themselves, of mobilizing the parties involved in these revolts.

As Searle analyzed the mobilizing force that these dramatic categories had within the context of the student revolts, he suggested that this force was in fact immense. For some of these dramatic categories sacralize (Searle himself appeals to the sacred) some states of affairs, some roles, some activities, etc., and once these categories become sacred, their pull is all the more impressive. This explains Searle's response to his rhetorical question, "why is it easier to believe mythology rather than fact?" (Searle believes that many of the views endorsed by the participants in the conflicts he studied were veritable cases of mythology - with only the most tenuous connection to reality.) Searle responded that "where the sacred is concerned, people's perceptions are rigidly shaped by their dramatic categories" (Searle 1971, 74). That is, the sacralization of the dramatic categories makes them much more determinant of behavior - and, to that same extent, then their relative absence in Searle's later social ontology is all the more noteworthy.

For Searle, part of the "anatomy of student revolts" (i.e., part of his early analysis of the social and institutional reality in which these revolts took place) is the following:

a) Perception is a function of expectation.

b) In extreme social situations, expectations of both observers and participants are a function of their dramatic categories. 
c) Where the dramatic categories have a sacred status, they have an especially strong effect on both perceptions and action.

d) In the three stages of student revolt [which are irrelevant for my purposes here], the movement from one stage to the next is brought about by triggering a sacred dramatic category (Searle 1971, 77f).

Quite significantly, we can see that Searle's of notion of power seems to play no prominent role (and at any rate, it is not the only thing that matters) in his account of the anatomy of student revolts. What seems to matter most are the dramatic categories. Conversely, Searle's own account of dramatic categories plays no prominent role in his theoretical social ontology.

While I cannot here undertake a full-blown investigation of these dramatic categories, one of their features is salient enough, and also enough for my sketching an objection to Searle's social ontology. Dramatic categories are, at least sometimes (though presumably always if they have been sacralized) appealing in themselves, i.e. they are intrinsically valuable. Sometimes their value is not merely a trace; not merely a result of the degeneration of other phenomena. The fact that dramatic categories can be socially constructed, does not affect my claim that their value is intrinsic. Something is valued intrinsically, if it is valued for its own sake; whether the reason why it is valued in the first place is the result of social constructions or not being a different issue.

In The Campus War, Searle presented five interesting "subcultures" which he suggested could be used in order to understand student revolts: i.e., the fraternity-sorority culture, the professional culture, the intellectual culture, the hippie culture, and the radical (political-activist) culture (Searle 1971, 45ff). These subcultures were to no small extent valued (or disvalued) in virtue of all sorts of dramatic categories; moreover, Searle believed that sometimes the adoption of one of these subcultures as one's own "is akin to a religious conversion". Searle was rather emphatic about this "religious quality", and about the "liturgical and ritualistic style" of the dramatic categories which help explain, in his estimation, the student revolts which he analyzed (Searle 1971, 59).

Searle further described the sort of attitude of many students at the time: rather than saying "here is our platform and here is how we intend to achieve our objectives,", they said: "here is our style and it is itself the objective, for it offers you meaning, fulfillment, and community, a chance, in short, to find yourself and a meaning in your life, a chance to avoid the hideous and bankrupt materialism of the world around you" (Searle 1971, 
59). Now, inventing or reinventing oneself as a representative of any of the cultural categories that Searle discussed in the context of his analysis of student revolts need not be disconnected from the attainment of powers (in the narrow sense of his social ontology). There is, however, no necessary connection between the dramatic categories and the attainment of powers: one may wish to personify this or that cultural category, without any interest in any power (in the narrow sense) whatsoever. That is, sometimes, at least, these sacred, liturgical, ritualistic, etc., phenomena, are valued in themselves. And sometimes mere places, titles, names, etc., can exhibit this sort of sacredness, and thus they are sometimes valued in themselves.

\section{Intrinsic Value and Society}

Early in his career Searle admitted, albeit tacitly, that some judgments of intrinsic value (at least those associated with dramatic categories) were terribly important in explaining the host of social and institutional phenomena associated with student revolts, and yet his explicit social ontology can hardly accommodate these phenomena. Interestingly, then, the young Searle's explanations of the student revolts in the United States in the sixties are not supported by his theoretical views on social ontology. In fact, to the extent that the only sort of normativity that Searle seems to admit enters into social and institutional phenomena is that arising from constitutive rules, it could be argued that Searle's social ontology not only ignores, but in effect excludes intrinsic value.

In closing, I would like to emphasize that intrinsic value is far from being just a matter of explaining aberrant behavior, as my appeal to The Campus War (in the sense that this book is concerned with problems in the working of societal institutions) may, perhaps, be taken to suggest. Recognizing, say via a medal, a hero's heroism, is valuable in itself. Recognizing heroism (with medals, say) is not merely the remnant of the powers which at an earlier time used to be associated with medals, as Searle claims. And this value is not the result of any interesting set of constitutive rules. The recognition of the hero, is not only morally appropriate, but arguably aesthetically appropriate as well. And these two types of normativity differ from the normativity of games and constitutive rules.

Consider, in contrast, the sorts of normative consequences that flow from that unique sort of normativity with which Searle is explicitly concerned. Just as some practices could not (logically) exist without some constitutive rules, the existence of constitutive rules, in Searle's opinion, 
endow social phenomena with "normative status". "This is shown", Searle continues, "by the fact that the general rule creates the possibility of abuses that could not exist without the rule, such as counterfeit money" (Searle 1971, 48, emphasis added). True, without some constitutive rules in place the very idea of counterfeiting would lose part, maybe an essential part, of its meaning; without a clear rule as to what is to count as money, the idea of counterfeit money does lose something. And this rule indeed brings in a normative dimension. But it is not the end of the story of normativity. Think of phenomena related to counterfeiting: faking, feigning, imposturing, and so on; some of them are sometimes criticizable, independently of any constitutive rules. But myriad of other moral phenomena exhibit a sort of intrinsic value which is independent of the sorts of considerations that matter to Searle: cruelty and envy, for example, are intrinsically bad; kindness and generosity are intrinsically good, and so on.

As G. E. Moore famously noted, moreover, the question of intrinsic value, is "the primary ethical question", and all other ethical questions are, in a sense, of lesser importance (Moore 1993, $53 \mathrm{ff}, 232 \mathrm{ff}$, and passim). And it is precisely an engagement with this question which is absent from Searle's social ontology, and insofar as ethical questions are a part of society, then this is a major problem facing any plausible social ontology.

Consider, as one last example (amongst many) of the importance of intrinsic value, the famous debate regarding the justification of punishment, which distinguishes between retributivism and consequentialism. As recent contributions to this age-old debate show, the best way of understanding retributivism (both its essence and its appeal) is to understand it as asserting that deserved punishment is intrinsically good (Zaibert 2006, $155 \mathrm{ff}$, and $202 \mathrm{ff}$ ).

That is, unlike more problematic forms of retributivism which assert that the fact that a wrongdoer deserves punishment makes it obligatory for us (the State, etc.) to punish her, what this fact entails is rather that, other things being equal, if the wrongdoer were to be punished, this punishment would be intrinsically good. The difference between these two forms of retributivism can hardly be overestimated. For the thesis which asserts the intrinsic goodness of deserved punishment does not create a duty to punish the deserving - and it does not reduce either to the toothless assertion that punishing the undeserving is a bad thing. That a given state of affairs is intrinsically good does not entail that we should bring it about; its goodness is defeasible - but it is still goodness 
This way of understanding retributivism dispels the much-discussed mystery or unintelligibility which supposedly surrounds retributive justifications of punishment, and it explains, too, how utilitarians can be retributivists (as G. E. Moore himself was). In some ways (the details of which are immensely complicated), the opposition between retributivism and consequentialism can be seen as one manifestation of a general problem between deontological and teleological normative theories. But, at bottom, one of the central aspects of these sorts of oppositions is simply the opposition between two types of normativity: the normativity associated to intrinsic value, and the normativity associated to constitutive rules and games.

Independently of the position that one may adopt regarding the justification of punishment or regarding any of the thorny debates belonging to axiology, Searle's social ontology, predicated upon an idiosyncratically narrow understanding of power, seems to endorse a comprehensive teleological outlook, without even acknowledging the opposition in which it stands to deontology. As long as Searle sees all normativity as a matter of constitutive rules, and all power as matter of grantings of prerogatives, he is prone to continue insisting on the implausible thesis that the value of all social phenomena is the mere trace of some long-lost power-related value.

Our (collective) recognition of, say, heroism, as well as our (collective) censure of, say, cruelty, are not only based on considerations of intrinsic value, but they are not the result of constitutive rules of any phenomena, nor do they stem from the meaning of any terms. It is incumbent upon a good social ontology to give an account of these phenomena, and Searle's social ontology fails to do this in a satisfactory manner.

\section{REFERENCES}

Gilbert, M. 1989 On Social Facts, London: Routledge.

Moore, G.E. 1993 Principia Ethica, (2 ${ }^{\text {nd }}$ ed.), Cambridge: Cambridge University Press.

Searle, J.R. 1964 “How to Derive an 'Ought' from 'Is"”, Philosophical Review, 73, 4358.

- 1969 Speech Acts: An Essay in the Philosophy of Language, Cambridge: Cambridge University Press.

- 1971 The Campus War: A Sympathetic Look at University in Agony, New York: World Publishing Company.

- 1995 The Construction of Social Reality, New York: Free Press. 
Tuomela, R. 1995 The Importance of Us: A Philosophical Study of Basic Social Notions, Palo Alto: Stanford University Press.

- 2002 The Philosophy of Social Practices: A Collective Acceptance View, Cambridge: Cambridge University Press.

Zaibert, L. and Smith, B. 2007 (forthcoming) "The Varieties of Normativity: An Essay on Social Ontology", in S. L. Tsohatzidis (ed.) Intentional Acts and Institutional Facts: Essays in John Searle's Social Ontology, Dordrecht: Springer.

- Zaibert, L. 2006 Punishment and Retribution, Aldershot: Ashgate. 